\begin{tabular}{cc|c}
\hline Tar. Bil. Der. & Tarım Bilimleri Dergisi & Journal of Agricultural Sciences \\
& $\begin{array}{c}\text { Dergi web sayfası: } \\
\text { www.agri.ankara.edu.tr/dergi }\end{array}$ & Journal homepage: \\
& www.agri.ankara.edu.tr/journal
\end{tabular}

\title{
Anason (Pimpinella anisum L.) ve Kimyon (Cuminum cyminum L.) Tohumlarının Uçucu Yağ Kompozisyonu ile Antimikrobiyal ve Antioksidan Özelliklerinin Belirlenmesi
}

\author{
Nesrin HAŞIMİ a , Veysel TOLAN ${ }^{b}$, Süleyman KIZIL ${ }^{\mathrm{c}}$, Ersin KILINÇ d \\ a Batman Üniversitesi, Sağlı Yüksekokulu, Beslenme ve Diyetetik Bölümü, 72060, Batman, TÜRKIYYE \\ ${ }^{\boldsymbol{b}}$ Dicle Üniversitesi, Fen Fakültesi, Biyoloji Bölümü, 21280, Diyarbakır, TÜRKIYE \\ ${ }^{c}$ Dicle Üniversitesi, Ziraat Fakültesi, Tarla Bitkileri Bölümü, 21280, Diyarbakır, TÜRKIYYE \\ ${ }^{d}$ Mardin Artuklu Üniversitesi, Sağllk Hizmetleri Yüksekokulu, Tıbbi Laboratuar Programı, 47000, Mardin, TÜRKIYE
}

\section{ESER BILGISİ}

Araştırma Makalesi — Bitkisel Üretim ～DOI: 10.1501/Tarimbil_0000001261

Sorumlu Yazar: Nesrin Haşimi, E-posta: nesrin.hasimi@batman.edu.tr, Tel: +90 (488) 2173500

Geliş Tarihi: 24 Nisan 2013, Düzeltmelerin Gelişi: 30 Aralık 2013, Kabul: 15 Ocak 2014

\begin{abstract}
ÖZET
Bu çalışmada, anason (Pimpinella anisum L.) ve kimyon (Cuminum cyminum L.) tohumlarının uçucu yağ bileşenleri ile bu yağların antimikrobiyal ve antioksidan özelliklerinin belirlenmesi amaçlanmıştır. Uçucu yağ bileşenleri GC/MS cihazı ile belirlenmiştir. Yağların antimikrobiyal özellikleri disk difüzyon yöntemi ile Gram pozitif (Staphylococcus aureus ATCC 25923, Streptococcus pyogenes ATCC 19615), Gram negatif (Escherichia coli ATCC 25922, Pseudomonas aeruginosa ATCC 27853) bakterileri ve maya (Candida albicans ATCC 10231) kullanılarak, antioksidan özellikler ise DPPH yöntemiyle belirlenmiştir. Anason uçucu yağının esas bileşeninin trans-anetol (\% 52.94) olduğu, bunu iso-anetol (\% 13.89), karyofillen oksit (\% 8.55) ve karyofillen (\% 4.29)'in izlediği; kimyon uçucu yağının ise sırası ile $\beta$-pinen $(\% 15.77), \alpha$ terpinen (\% 15.52), 1-fenil-1-butanol (\% 15.13) ve kuminik aldehit (\% 12.74) içerdiği saptanmıştır. Anason uçucu yağının mikroorganizmalar üzerinde düşük, kimyon uçucu yağının ise orta derecede antimikrobiyal aktivite gösterdiği saptanmıştır. Kimyon uçucu yağı C. albicans'a karşı $22 \pm 0.9$ mm'lik inhibisyon zon çapı ile yüksek antimikrobiyal aktivite göstermiştir. P. aeruginosa her iki uçucu yağa karşı direnç göstermiştir. Kimyon uçucu yağının antioksidan aktivitesi (\% 75.60) askorbik asit aktivitesine (\% 78.75) yakın, BHA (\% 50.45) ve BHT (\% 23.54) aktivitesinden daha yüksek bulunmuştur. Anason düşük antioksidan aktivite (\% 23.24) göstermiş olmasına rağmen BHT ile benzer aktivite göstermiştir. Çalışmada kullanılan örneklerin aktivite sıralaması askorbik asit $>$ kimyon $>$ BHA $>$ BHT $>$ anason şeklinde gerçekleşmiştir.

Anahtar Kelimeler: Anason; Kimyon; Uçucu yağ; Antimikrobiyal aktivite; Antioksidan aktivite
\end{abstract}

\section{Determination of Essential Oil Composition, Antimicrobial and Antioxidant Properties of Anise (Pimpinella anisum L.) and Cumin (Cuminum cyminum L.) Seeds}

\author{
ARTICLE INFO \\ Research Article - Crop Production \\ Corresponding Author: Nesrin Haşimi, E-mail: nesrin.hasimi@batman.edu.tr, Tel: +90 (488) 2173500 \\ Received: 24 April 2013, Received in Revised Form: 30 December 2013, Accepted: 15 January 2014
}




\begin{abstract}
In this research, the essential oil components, antimicrobial and antioxidant properties of anise (Pimpinella anisum L.) and cumin (Cuminum cyminum L.) seed oils were investigated. The essential oil components determined by GC/MS instrument. The antimicrobial activity determined by disc diffusion method against the gram negative bacteria, namely Escherichia coli ATCC 25922, Pseudomonas aeruginosa ATCC 27853, the gram positive bacteria namely Staphylococcus aureus ATCC 25923, Streptococcus pyogenes ATCC19615 and Candida albicans ATCC10231 as the yeast. The antioxidant activities of essential oils were carried out by DPPH free radical scavenging activity method. It was determined that the main components of the anise essential oil were trans-anethole (52.94\%) followed by iso-anethole (13.89\%), caryophllene oxide (8.55\%) and caryophyllene $(29.4 \%)$; the main components of the cumin essential oil were $\beta$-pinene (15.77\%), $\alpha$-terpinene (15:52\%), 1-Phenyl-1-butanol (15:13\%), cumic aldehyde (12.74\%) respectively. Anise essential oil showed weak antimicrobial activity and cumin essential oil showed moderate antimicrobial activity against test microorganisms. Cumin essential oil showed strong antimicrobial activity against C. albicans with $22 \pm 0.9$ $\mathrm{mm}$ inhibition zone diameter. P. aeruginosa showed resistance to both essential oils. The antioxidant activity of cumin essential oil (75.60\%) was observed closer to ascorbic acid (78.75\%), higher than BHA (50.45\%) and BHT (23.54\%). Although anise essential oil exhibited low activity, it has the similar activity with BHT. The scavenging activity of the samples decreasing order was ascorbic acid $>$ cumin $>$ BHA $>$ BHT $>$ anise.
\end{abstract}

Keywords: Anise; Cumin; Essential oil; Antimicrobial activity; Antioxidant activity

(C) Ankara Üniversitesi Ziraat Fakültesi

\section{Giriş}

Dünya nüfusunun yaklaşık \% 70-80’i bitki kaynaklı geleneksel tıp uygulamaları ile tedavi görmektedir. İnsanlar bitki ekstrelerini tedavi amaçlı ilaç, şurup, tablet ve oral sprey şeklinde stres azaltıcı, yorgunluk ve uykusuzluk giderici ve sinirsel bazı hastalıkların tedavisinde de yaygın olarak kullanmaktadırlar (Arceusz et al 2010).

Uçucu yağlar bitkilerden elde edilir ve kimyasal olarak birçok bileşen içeririler. Bazen bir yağda 100 'den fazla bileşen bulunabilmektedir. Her uçucu yağın kendine özgü kokusu ve aromaterapik özellikleri, söz konusu yağı oluşturan bileşenlerin kombinasyonu ve miktarına bağlıdır (Carrapiso et al 2002). Uçucu yağların antimikrobiyal, antioksidan, antikanser vb. gibi birçok fonksiyonel özelliğe sahip oldukları belirlendikten sonra (Hammer et al 1999; Jayaprakasha et al 2002; Lee \& Shibamoto 2002; Vardar-Ünlü et al 2003) birçok araştırma grubu, uçucu yağların farmokolojik özelliklerinin araştırılmasına odaklanmıştır.

Anason ve kimyon Apaiaceae familyasına ait, aroma ve tedavi edici özelliklerinden dolayı ticari öneme sahip, Asya, Afrika ve Avrupa'da tarımı yapılan ilk bitkilerdir. Kimyon tohumu gidalarda tatlandırıcı, geleneksel tıpta diş ağrısı, hazımsızlık, ishal, epilepsi ve sarılık tedavisinde yaygın olarak kullanılan popüler baharatlardan biridir (Thippeswamy \& Naidu 2005). Ayrıca, diüretik, gaz giderici, sindirimi kolaylaştırıcı, antispazmodik, sıkılaştırıcı etkiye sahip olduğu; hafif sindirim bozuklukları, mide bulantısı, kolik, dispeptik baş ağrısı ve şişkinlik tedavisinde kullanıldığı ve karaciğer fonksiyonunu artırdığı bildirilmiştir (Janahmadi et al 2006).

Anason, eczacilık, parfüm ve gıda endüstrisinde kullanılan önemli bir baharat ve tıbbi bitkidir. Uçucu yağ1 antispazmodik, antioksidan, antimikrobiyal, insekdisidal ve antifungal özelliklere sahiptir (Tunc \& Sahinkaya 1998; Gülcin et al 2003; Özcan \& Chalchat 2006; Tepe et al 2006; Tirapelli et al 2007). Anason tıbbi olarak dispeptik şikâyetlerde, nezle tedavisinde ve hafif balgam söktürücü olarak kullanılır (Blumenthal 1999).

$\mathrm{Bu}$ çalışma ile yaygın olarak tüketilen kimyon ve anason bitkilerinin tohumlarına ait uçucu yağın bileşenleri ve bu yağların antimikrobiyal ve antioksidan aktivitesinin belirlenmesi amaçlanmıştır. 


\section{Materyal ve Yöntem}

\subsection{Bitkisel materyal}

Çalışmada materyal olarak anason ve kimyon bitkilerinin olgunlaşmış tohumları kullanılmıştır. Tohum örnekleri Dicle Üniversitesi Ziraat Fakültesi Tarla Bitkileri Bölümü, Tıbbi ve Aromatik Bitkiler Tohumluk Koleksiyonundan temin edilmiştir.

\subsection{Uçucu yăg ekstraksiyonu}

Baharat uçucu yağları; ögütülmüş tohum örneklerinden $30 \mathrm{~g}$ alınarak Clevenger cihazında 3 saat süre ile ekstraksiyona tabi tutulmuştur $\left(\mathrm{V} \mathrm{W}^{-1} \%\right)$.

\subsection{GC/MS analizi}

Anason ve kimyon tohumlarına ait uçucu yağlar GC Clarus 600-MS Clarus 600 C (Perkin Elmer) cihazında analiz edilmiştir. Kromatografik çalışma Elite 5-MS kapiler kolonda (\% 5 Diphenyl)Dimethylpolysiloxane, $0.25 \mathrm{~mm}$ i.d.x30 m, film kalınlığ $0.25 \mu \mathrm{m})$ split metot $(1 / 20)$ kullanılarak yapılmıştır. Taşıyıcı gaz olarak helyum $1.0 \mathrm{~mL} \mathrm{dak}^{-1}$ akış hızında kullanılmıştır. Kolon sıcaklığ $60{ }^{\circ} \mathrm{C}$ 'de 3 dakika bekletilmiş, $4{ }^{\circ} \mathrm{C}$ dakika ${ }^{-1}$ artış hızıyla 130 ${ }^{\circ} \mathrm{C}$ 'ye yükseltilerek 3 dakika bekletilmiş daha sonra dakikada $20{ }^{\circ} \mathrm{C}$ dakika ${ }^{-1}$ artış hızıyla $240{ }^{\circ} \mathrm{C}^{\prime}$ ye çıkarılmış ve bu sıcaklıkta 2 dakika bekletilmiştir. Ayrılan bileşenler NIST (National Institute of Standards and Technology), WILEY 8 ve NBS kütüphaneleri taranarak tespit edilmiştir.

\subsection{Antimikrobiyal aktivite}

Antimikrobiyal aktivite gram pozitif (Staphylococcus aureus ATCC 25923, Streptococcus pyogenes ATCC 19615), Gram negatif (Escherichia coli ATCC 25922, Pseudomonas aeruginosa ATCC 27853) bakteriler ve maya (Candida albicans ATCC 10231) kullanılarak belirlenmiştir. Kullanılan mikroorganizmalar Refik Saydam Hifzıssıhha Merkezi'nden (Ankara, Türkiye) satın alınmıştır.

Antimikrobiyal aktiviteyi belirlemek için Disk Difüzyon yöntemi uygulanmıştır (NCCLS 1997). Taze kültürden öze ile alınan mikroorganizmalar nutrient broth (NB) sivi besi yerinde $0.5 \mathrm{Mc}$ Farland'a eşit türbidite oluşana kadar $37{ }^{\circ} \mathrm{C}$ 'de inkübe edilmiştir. Kültürü hazırlanan test mikroorganizmalarından $100 \mu \mathrm{L}$ alınarak nutrient agar katı besi yerine yayma ekim yapılarak, 5 ve 10 $\mu \mathrm{L}$ uçucu yağ emdirilmiş steril diskler ekim yapılan petrilere yerleştirilmiştir. E. coli, $P$. aeruginosa, $S$. aureus ve $S$. pyogenes bakterileri için $37^{\circ} \mathrm{C}$ 'de 24 saatlik inkübasyon; C. albicans için $30{ }^{\circ} \mathrm{C}$ 'de 48 saatlik inkübasyondan sonra inhibisyon zon çapları ölçülmüştür. Aynı işlem pozitif kontrol (imipenem $(10 \mu \mathrm{g})$ ve nystatin $(30 \mu \mathrm{g}))$ için de tekrarlanmıştır. Her test farklı zamanlarda 3 tekrar halinde gerçekleştirilmiştir.

\subsection{Antioksidan aktivite}

Uçucu yağların 1,1-difenil-2-pikrilhidrazil (DPPH) üzerindeki serbest radikal süpürücü etkileri Blois'in (1958) geliştirdiği yönteme göre yapılmıştır. $\mathrm{Bu}$ yöntemde; 5 mL \% 0.004 metanol DPPH çözeltisine uçucu yağlardan $50 \mu \mathrm{L}$ ilave edilerek karanlıkta oda sıcaklığında 30 dakika inkübasyonun ardından 517 nm'de spektrofotometrik ölçüm alınmıştır. Pozitif kontrol olarak bütillenmiş hidroksi anisol (BHA), butillenmiş hidroksi toluen (BHT) ve askorbik asit kullanılmıştır. DPPH serbest radikalini inhibisyon yüzdesi (I \%) aşağıdaki formüle göre hesaplanmıştır. Her test farklı zamanlarda 3 tekrar halinde gerçekleştirilmiştir.

$\% \mathrm{I}=\left(\mathrm{A}_{0}-\mathrm{A}_{1} / \mathrm{A}_{0}\right) \times 100\left(\mathrm{~A}_{0}\right.$, kontrol absorbansi; $\mathrm{A}_{1}$, numune absorbans1)

\subsection{Verilerin analizi}

Analizler farklı zamanlarda gerçekleştirilen 3 tekrarlı olarak yapılmıştır. Sonuçların ortalamaları standart sapma ile birlikte verilmiştir.

\section{Bulgular ve Tartışma}

\subsection{GC/MS analizi}

Anason ve kimyon tohumlarının uçucu yağ bileşenlerine ait sonuçlar Çizelge 1'de verilmiştir. Anason uçucu yağ oranının \% 1.94, esas bileşeninin ise trans-anetol (\% 52.94) olduğu belirlenmiştir. $\mathrm{Bu}$ sonuç anason uçucu yağının kimyasal kompozisyonu üzerine yapılmış önceki çalışmalarla benzerlik göstermektedir (Maheshwari et al 1989; 
Orav et al 2008; Yan et al 2011). Iso-anetol (\% 13.89), karyofillen oksit ( $\% 8.55)$, karyofillen (\% 4.29), isopropil miristat ( $\%$ 2.83), $\alpha$-himalen ( $\%$ 2.68) ve 5-benzosiklooktenol (\% 2.34) anason uçucu yağındaki diğer bileşenlerdir.

Akgül (1993), anason uçucu yağının başlıca bileșenlerinin trans-anetol (\% 80-95), metil kavikol (\% 1-2) ve anisaldehit (\% 1) olduğunu bildirmiştir. Anetol'ün izomeri olan cis-anetol'ün toksik etkisinden dolayı pek istenmediğini bildirmiştir.

Skalicka-Wozniak et al (2013), anason uçucu yağının başlıca bileşeninin anetol ( $\%$ 74.58) olduğunu ve bunu estragol (\% 7.33), foenikulin (\% 3.31), linalol (\% 2.25), $p$-anisaldehit (\% 2.09), limonen (\% 1.45), $\beta$-karyofillen $(\%$ 1.25) ve p-asetonilanisol (\% 1.14)'un izlediğini bildirmiştir.

Avrupa Farmakopesi anason uçucu yağındaki estragol miktarını \% $0.5-6.0$ arasında sınırlandırmıştır. Çalışmamızda estragol oranı \% 1.97 olarak belirlenmiştir ki bu değer Avrupa Farmakopesi'nin belirlediği sınırlar içindedir. Gidalarda tatlandırıcı olarak kullanılan estragol'un genotoksik etkiye sahip olduğunun ortaya konması

Çizelge 1- Anason ve kimyon tohumlarına ait uçucu yağların GC/MS analiz sonuçları (\%)

Table 1- The GC/MS analysis results (\%) of essential oils of anise and cumin seeds

\begin{tabular}{|c|c|c|c|c|c|}
\hline Bileşenler & $R T$ & P. anisum & Bileşenler & $R T$ & C. cyminum \\
\hline Linalol & 11.20 & 0.13 & 3-Thujen & 5.64 & 0.38 \\
\hline Estragol & 14.55 & 1.97 & Pinen & 5.85 & 1.02 \\
\hline Anetol & 16.37 & 0.12 & Sabinen & 6.98 & 0.71 \\
\hline p-anisaldehit & 16.58 & 1.86 & $\beta$-pinen & 7.19 & 15.77 \\
\hline trans-anetol & 17.82 & 52.94 & $\beta$-mirsen & 7.48 & 1.11 \\
\hline Mirtenal & 17.88 & 0.55 & $\alpha$-fellandren & 8.01 & 1.57 \\
\hline Iso-anetol & 18.04 & 13.89 & $p$-simen & 8.64 & 6.43 \\
\hline Caryofillen & 21.86 & 4.29 & D-Limonen & 8.76 & 0.60 \\
\hline$\alpha$-himaçalen & 23.05 & 2.68 & $\beta$-fellandren & 8.80 & 0.47 \\
\hline$\beta$-vatirenen & 23.72 & 1.88 & $\alpha$-terpinen & 9.81 & 15.52 \\
\hline Eremofilen & 24.15 & 2.17 & Terpinolen & 10.64 & 8.42 \\
\hline Kurkumen & 24.25 & 0.74 & 4-terpinenol & 13.95 & 0.61 \\
\hline Isohomogenol & 24.48 & 0.96 & 1,3-siklohekzadien & 14.46 & 1.35 \\
\hline$\alpha$-longipinen & 24.68 & 0.71 & Kuminik aldehit & 16.17 & 12.74 \\
\hline$\beta$-bisabolen & 24.87 & 0.55 & 2-karen-10-al & 17.60 & 4.32 \\
\hline 5-benzosiklooktenol & 25.02 & 2.34 & 1-fenil-1-butanol & 17.83 & 15.13 \\
\hline Karyofillen oxit & 26.05 & 8.55 & Timol & 18.01 & 0.89 \\
\hline Isopropil Miristat & 28.17 & 2.83 & $p$-menta-1,4-dien-7-ol & 18.96 & 2.78 \\
\hline Ojenol & 28.23 & 0.54 & $\beta$-Gurjunen & 20.47 & 2.39 \\
\hline Toplam & & 99.7 & Karyofillen & 21.84 & 1.02 \\
\hline \multirow[t]{11}{*}{ Uçucu yağ oranı (\%) } & & 1.94 & $\alpha$-bergamoten & 22.40 & 1.06 \\
\hline & & & $(Z)$ - $\beta$-farnesen & 23.27 & 1.14 \\
\hline & & & $(-)-\alpha$-kubeben & 23.93 & 0.47 \\
\hline & & & Akoradien & 24.02 & 0.48 \\
\hline & & & $\beta$-bisabolen & 24.87 & 1.08 \\
\hline & & & Karyofillene oxit & 26.05 & 0.27 \\
\hline & & & $(+)$-karotol & 26.30 & 0.40 \\
\hline & & & Andesen & 27.13 & 0.99 \\
\hline & & & Isopropil Miristat & 28.16 & 0.31 \\
\hline & & & Toplam & & 99.43 \\
\hline & & & Uçucu yağ oranı $(\%)$ & & 2.46 \\
\hline
\end{tabular}

RT, tutulma zamanı 
sonucunda estragol gidalarda tat verici olarak kullanılanlar listesinden çıkartılmıştır (Burt 2004).

Kimyonda uçucu yağ oranı \% 2.46 olarak belirlenmiştir. Uçucu yağın ana bileşenleri sırası ile $\beta$-pinen ( $\%$ 15.77), $\alpha$ - terpinen ( $\% 15.52$ ), 1-fenil1-butanol (\% 15.13), kuminik aldehit (\% 12.74) ve terpineolen (\% 8.42)'dir (Çizelge 1).

Baser et al (1992) ve Borges ve Pino (1993) Türkiye'de yetişen kimyon tohumları uçucu yağının yüksek miktarda kuminaldehit, $p$-menta1,3-dien-7-al, $\quad p$-menta-1,4-dien-7-al, $\gamma$-terpinen, $p$-simen, $\beta$-pinen ve perilaldehit içerdiğini bildirmişlerdir. Rebey et al (2012), kimyon uçucu yağının $\gamma$-terpinen (\%25.58), 1-fenil-1,2 etandiol (\%23.16), kuminaldehit (\%15.31) ve $\beta$-pinen (\% 15.16) içerdiğini bildirmiştir. Kimyonda bitkinin farklı organlarında değişen oranlarda uçucu yağ bulunduğu, bu oranın bitkinin köklerinde \% 0.03 , gövde ve yapraklarında $\% 0.1$ ve çiçeklerinde $\%$ 1.7 olduğu, uçucu yağın ana bileşenler olarak bornil asetat ( $\%$ 23), $\alpha$-terpinen ( $\%$ 34) ve $\gamma$-terpinen (\% 51) içerdiği bildirilmektedir (Bettaieb et al 2010). Kimyon meyvelerinde uçucu yağ oranı $\% 2.3$ ile 5 arasında değişmektedir. Yağın major bileşeni olan kuminik aldehit \% 40-65 oranındadır. Bunun yanında perilla aldehit, kumin alkol, $\alpha$ ve $\beta$ pinen, dipenten, $p$-simen, $\beta$-fellandren ve limonen bileşenleri de bulunmaktadır (Hornok 1992).

\subsection{Antimikrobiyal aktivite}

Uçucu yağların antimikrobiyal aktiviteleri disk difüzyon yöntemine göre belirlenmiş olup, sonuçlar
Çizelge 2'de verilmiştir. Her iki uçucu yağın $P$. aeruginosa dışındaki mikroorganizmalar üzerinde antimikrobiyal aktivitesinin olduğu belirlenmiştir. Anason uçucu yağının çalışılan mikroorganizmalar üzerinde düşük (inhibisyon zonu $<12 \mathrm{~mm}$ ), kimyon uçucu yağının ise orta derecede (inhibisyon zonu $<20-12 \mathrm{~mm}$ ) antimikrobiyal aktivite gösterdiği saptanmıştır. Kimyon uçucu yağının $10 \mu \mathrm{L}$ uygulamada $22 \pm 0.9$ mm'lik inhibisyon zon çapı ile C. albicans'a karşı yüksek antimikrobiyal aktivite (inhibisyon zonu $>20 \mathrm{~mm}$ ) gösterdiği ve bu değerin pozitif kontrol olarak kullanılan, antifungal ajan olan nystatinin gösterdiği aktiviteye $(25.5 \pm 0.6 \mathrm{~mm})$ çok yakın bir değer olduğu görülmektedir. Aynı şekilde kimyon uçucu yağının $10 \mu \mathrm{L}$ uygulamada E.coli'ye karş1 gösterdiği aktivitenin $(18.33 \pm 0.3$ $\mathrm{mm}$ inhibisyon zon çapı) pozitif kontrol olarak kullanılan imipenemin gösterdiği antimikrobiyal aktiviteye $(19 \pm 0.8 \mathrm{~mm})$ çok yakın bir değer olduğu görülmektedir.

Tepe et al (2006), P. anisetum ve P. flabellifolia uçucu yağlarının antimikrobiyal aktivitelerini sekiz mikroorganizma üzerinde test etmiş ve uçucu yağların orta derecede antimikrobiyal aktiviteye sahip olduğunu bildirmişlerdir. Ramadan et al (2012), kimyon uçucu yağının antimikrobiyal aktivitesini araştırdıkları çalışmada uçucu yağın çeşitli mikroorganizmalara karşı $9-13 \quad \mathrm{~mm}$ inhibisyon zon çapı ile antimikrobiyal aktivite gösterdiğini bildirmişlerdir.

Çizelge 2-Anason ve kimyon tohumlarının uçucu yağlarının ve pozitif kontrollerin antimikrobiyal aktiviteleri

Table 2-The antimicrobial activity of essential oils of anise and cumin seeds and positive controls

\begin{tabular}{|c|c|c|c|c|c|}
\hline \multirow{3}{*}{ Test mikroorganizmaları } & \multicolumn{5}{|c|}{ İnhibisyon zon çapları (mm) } \\
\hline & \multicolumn{2}{|c|}{ Anason } & \multicolumn{2}{|c|}{ Kimyon } & \multirow{2}{*}{ Pozitif kontrol ${ }^{a}$} \\
\hline & $5 \mu L$ & $10 \mu L$ & $5 \mu L$ & $10 \mu L$ & \\
\hline E. coli ATCC 25922 & $12 \pm 0.3$ & $12 \pm 0.1$ & $15.66 \pm 0.2$ & $18.33 \pm 0.3$ & $19 \pm 0.8$ \\
\hline P. aeruginosa ATCC 27853 & ZY & ZY & ZY & ZY & $12 \pm 0$ \\
\hline S. aureus ATCC 25923 & $11 \pm 0.5$ & $12 \pm 0.4$ & $14 \pm 0.72$ & $18.33 \pm 0.53$ & $27.5 \pm 0.7$ \\
\hline S.pyogenes ATCC 19615 & $9 \pm 0.2$ & $12 \pm 0.7$ & $17 \pm 0.61$ & $17.66 \pm 0.55$ & $39.5 \pm 0.7$ \\
\hline C. albicans ATCC 10231 & $8.33 \pm 0.5$ & $11.66 \pm 0.9$ & $13.66 \pm 0.5$ & $22 \pm 0.9$ & $25.5 \pm 0.6$ \\
\hline
\end{tabular}

a, bakteriler için imipenem $(10 \mu \mathrm{g})$ maya için nystatin $(30 \mu \mathrm{g})$ kullanılmıştır; ZY, zon yok 
Gıda kaynaklı hastalıklar gelişmekte olan ve gelişmiş ülkelerde giderek büyüyen bir halk sağlığı sorunudur. Dolayısıyla mikrobiyal kaynaklı gıda bozulmalarını önleyebilecek aktif molekül arayışı araştırmacıların ilgisini çekmektedir. Sayısız kimyasal bileşiği sentezleme potansiyeline sahip olan bitkiler, bu çalışmaların odağını oluşturmaktadır.

\subsection{Antioksidan aktivite}

Doğal antioksidanların kaynağı ve kullanımı ile ilgili çok sayıda araştırma sonucu bulunmaktadır. Bazı baharatların antioksidan kapasitelerinin, sentetik antioksidanlardan daha fazla olduğu kanıtlanmıştır (Kizil et al 2010a; Kizil et al 2010b; Baydar et al 2011).

Anason ve kimyon tohumlarına ait uçucu yağlarının antioksidan kapasiteleri DPPH serbest radikal süpürücü aktivitelerine göre belirlenmiş ve sonuçlar Çizelge 3'te verilmiştir. Buna göre; kimyon ( $\% 75.60)$, en yüksek aktivite gösteren askorbik asit'e (\% 78.75) çok yakın, BHT (\% 23.54) ve BHA'dan (\% 50.45) yüksek antioksidan aktivite göstermiştir.

Anason uçucu yağı ise \% 23.24 inhibisyonla düşük aktivite göstermiş olmakla beraber BHT ile benzer aktiviteye sahiptir. Elde edilen sonuçlara göre; çalışmada kullanılan uçucu yağlar ve pozitif kontrollerin aktivite siralaması askorbik asit $>$ kimyon $>$ BHA $>$ BHT $>$ anason şeklinde gerçekleşmiş̧ir.

Gülçin et al (2003) anason tohumlarının su ve etanol ekstrelerinin DPPH süpürücü etkisini araştırmış ve su ekstresinin \% 86.38, etanol ekstresinin \% 53.22 inhibisyon gösterdiğini bildirmiştir. Aynı şekilde Al-İsmail \& Aburjai (2004) de çalışmalarında anason tohumlarının su ekstresinin $0.08 \mathrm{mg} \mathrm{mL}^{-1}$ konsantrasyonda \% 90.1, etanol ekstresinin ise $0.2 \mathrm{mg} \mathrm{mL}^{-1}$ konsantrasyonda $\% 88.3$ inhibisyon gösterdiğini bildirmişlerdir.

Anason uçucu yağının kimyasal içeriğine bakıldığında \% 52.94 oranında trans-anetol içerdiği görülmektedir. Bilindiği gibi trans-anetol bir monoterpendir. Monoterpen içeriği yüksek
Çizelge 3- Pozitif kontrol olarak kullanılan askorbik asit, BHT ve BHA ile birlikte anason ve kimyon tohumlarının uçucu yağlarının antioksidan aktiviteleri

Table 3- The antioxidant activity of essential oils of anise and cumin seeds together with the Ascorbic acid $B H T$ and BHA used as a positive controls

\begin{tabular}{lc}
\hline Örnekler & $\% I$ \\
\hline Askorbik Asit & $78.75 \pm 12.84$ \\
BHT & $23.54 \pm 1.98$ \\
BHA & $50.45 \pm 1.04$ \\
Kimyon & $75.60 \pm 9.95$ \\
Anason & $23.24 \pm 2.74$ \\
\hline
\end{tabular}

olan yağların antioksidan aktivitede etkisiz olduğu daha önce Ruberto \& Baratto (2000) tarafindan bildirilmiştir. Anason uçucu yağının gösterdiği düşük inhibisyonun sebebinin yapısındaki monoterpenler olabileceği düşünülmektedir.

Kimyonun antioksidan aktivitesi Çizelge 3 'te de görüldüğü gibi \% 78.75 'dir. Sultana et al (2010) Bangladeş'te kullanılan bazı baharatların antioksidan aktiviteleri üzerine yaptıkları çalışmada kimyonda $15.48 \mu \mathrm{g} \mathrm{mL}^{-1} \mathrm{IC}_{50}$ değeri ile askorbik asitten $\left(\mathrm{IC}_{50}=22.78 \mu \mathrm{g} \mathrm{mL}^{-1}\right)$ daha yüksek aktivite elde etmişlerdir. El- Ghorab et al (2010) yaptıkları çalışmada kimyon uçucu yağının \% 85.44 inhibisyonla yüksek antioksidan aktivite gösterdiğini bildirmişlerdir. El- Ghorab et al bu aktivitenin uçucu yağın içerdiği kuminal, $\gamma$-terpinen, pinokarveol, karotol, $\alpha$-pinen, sabinen, $\beta$-terpineol ve linalool gibi antioksidan bileşiklerden kaynaklanabileceğini bildirmektedirler. Einafshar et al (2012), kimyon uçucu yağının antioksidan kapasitesini DPPH radikal süpürücü aktivitesine göre araştırmış ve $\mathrm{EC}_{50}$ değerini $1.20 \mathrm{mg} \mathrm{mL}^{-1}$ olarak belirlemişlerdir. Araştırmacılar serbest radikal süpürme etkisinin büyük ölçüde fenolik madde içeriği ile ilişkili olduğunu bildirmişlerdir.

Çalışmamızda kimyon uçucu yağı ile elde edilen aktivite, uçucu yağın içerdiği $\alpha$-terpinen, $\beta$-pinen, 1-fenil-1-butanol, kuminik aldehit, terpinolen ve $p$-simen gibi bileşiklerden kaynaklı olabileceği gibi tüm uçucu yağ bileşenlerinin sinerjik etkisinden de kaynaklanmış olabileceği düşünülmektedir. 


\section{Sonuçlar}

Gıda sektöründe doğal katk1 maddelerinin kullanımının yaygınlaşması ile birlikte bitkilerde bulunan doğal antioksidanlara olan ilgi gün geçtikçe artmaktadır. $\mathrm{Bu}$ nedenle doğal antioksidanların incelenmesi, son zamanlarda popüler bir çalışma alanı haline gelmiştir. Türkiye'nin tıbbi bitki ticaretinde baharat bitkileri ve özellikle anason ve kimyon önemli bir yer tutmaktadır. Bununla birlikte, aromatik bitkiler ve baharatların antioksidan ve antimikrobiyal özelliklerinin bilinmesi, insan sağlığ ve gıda ürünlerinin raf ömrünü uzatmak açısından ilaç ve gıda endüstrisine önemli katkı sağlayacaktır. Sonuç olarak; anason ve kimyon uçucu yağları esas bileşen olarak sırasıyla trans anetol ve $\beta$-pinen içerdiği, kimyon uçucu yağının anason uçucu yağına göre daha yüksek antimikrobiyal ve antioksidan aktivite gösterdiği belirlenmiştir.

\section{Kaynaklar}

Akgül A (1993). Baharat Bilimi ve Teknolojisi. Gida Teknolojisi Derneği Yayınları: 15, Ankara

Al-Ismail K M \& Aburjai T (2004). Antioxidant activity of water and alcohol extracts of chamomile flowers, anise seeds and dill seeds. Journal of the Science of Food and Agriculture 84(2): 173-178

Anli E R \& Bayram M (2010). Traditional anti-seed flavoured spirit drinks. Food Reviews International 26(3): 246-269

Arceusz A, Radecka I \& Wesolowski M (2010). Identification of diversity in elements content in medicinal plants belonging to different plant families. Food Chemistry 120:(1) 52-58

Arslan N, Gurbuz B \& Sarihan E O (2004). Variation in essential oil content and composition in Turkish anise (Pimpinella anisum L.) populations. Turkish Journal of Agriculture \& Forestry 28:173-177

Ateş D A \& Erdoğrul Ö T (2003). Antimicrobial activities of various medicinal and commercial plant extracts. Turkish Journal of Biology 27:157-62

Baser K H C, Kurkcuoglu M \& Ozek T (1992). Composition of the Turkish cumin seed oil. Journal of Essential Oil Research 4: 133-138

Baydar N G, Babalık Z, Türk F H \& Çetin E S (2011). Phenolic composition and antioxidant activities of wines and extracts of some grape varieties grown in Turkey. Tartm Bilimleri Dergisi 17: 67-76

Bettaieb I, Bourgou S, Wannes W A, Hamrouni, I, Limam F \& Marzouk B (2010). Essential oils, phenolics and antioxidant activities of different parts of cumin (Cuminum cyminum L.). Journal of Agricultural and Food Chemistry 58(19): 10410-10418

Blois M S (1958). Antioxidant determination by the use of a stable free radical. Nature 181: 1199-1200

Blumenthal M(1999). The Complete German Commission E Monographs, therapeutic guide to herbal medicines. American Botanical Council, Austin, Texas

Borges P \& Pino J (1993). The isolation of volatile oil from cumin seeds by steam distillation. Die Nahurung 37(2): 123-126

Burt S (2004). Essential oils: their antibacterial properties and potential applications in foods - a review. International Journal of Food Microbiology 94: 223253

Carrapiso A I, Ventanas J \& Garcia C (2002). Characterization of the most odor-active compounds of Iberian ham headspace. Journal of Agricultural and Food Chemistry 50(7): 1996-2000

Einafshar S, Poorazrang H, Farhoosh R \& Seiedi S M (2012). Antioxidant activity of the essential oil and methanolic extract of cumin seed (Cuminum cyminum). European Journal of Lipid Science and Technology 114:168-174

El-Ghorab A H, Nauman M, Anjum F M, Hussain S \& Nadeem M (2010). A comparative study on chemical composition and antioxidant activity of ginger (Zingiber officinale) and cumin (Cuminum cyminum). Journal of Agricultural and Food Chemistry 58(14): 8231-8237

Gülçin I, Oktay M, Kireçci E \& Küfrevioğlu Ö I (2003). Screening of antioxidant and antimicrobial activities of anise (Pimpinella anisum L.) seed extracts. Food Chemistry 83(3): 371-382

Hammer K A, Carson C F \& Riley T V (1999). Antimicrobial activity of essential oils and other plant extracts. Journal of Applied Microbiology 86(6): 985-990

Hornok L (1992). The Cultivation of Medicinal Plants. In: Hornok L (Ed.), Cultivation and Processing of Medicinal Plants, John Wiley and Sons, Budapest, pp. 289-290 
Janahmadi M, Niazi F, Danyali S \& Kamalinejad M (2006). Effects of the fruit essential oil of Cumin seed Linn. (Apiaceae) on pentylen etetrazol induced epileptic form activity in F1 neurons of Helix aspersa. Journal of Ethnopharmacology 104(1-2): 278-282

Jayaprakasha G K, Negi P S \& Sakariah K K (2002). Evaluation of antioxidant activities and antimutagenicity of turmeric oil: A byproduct from curcumin production. Zeitschrift Fur Naturforschung C-A Journal of Biosciences 57(9-10): 828-835

Kizil S, Hasimi N, Tolan V, Kilinç E \& Karatas H (2010a). chemical composition, antimicrobial and antioxidant activities of hyssop (Hyssopus officinalis L.) essential oil. Notulae Botanicae Horti Agrobotanici ClujNapoca 38(3): 99-103

Kizil S, Hasimi N, Tolan V, Kilinç E \& Yuksel U (2010b). Mineral content, essential oil components and biological activity of two mentha species (M. piperita L., M. spicata L.). Turkish Journal of Field Crops 15(2): 148-153

Lee K G \& Shibamoto T (2002). Determination of antioxidant potential of volatile extracts isolated from various herbs and spices. Journal of Agricultural and Food Chemistry 50(17): 4947-4952

Maheshwari S K, Gangrade S K \& Tarivedi KC (1989). Effect of date and method of sowing on grain and oil yield and oil quality of anise. Indian Perfumer 33: 169-173

NCCLS (National Committee for Clinical Laboratory Standards) (1997). Performance Standards for Antimicrobial Disk Susceptibility Test; $6^{\text {th }}$ ed. Approved Standard, Wayne Pa. M2-A6

Orav A, Raal A \& Arak E (2008). Essential oil composition of Pimpinella anisum L. fruits from various European countries. Natural Product Research 22(3): 227-232

Özcan M M \& Chalchat J C (2006). Chemical composition and antifungal effect of anise (Pimpinella anisum L.) fruit oil at ripening stage. Annals of Microbiology 56(4): 353-358

Ramadan M F, Asker MMS \& Tadros M (2012). Antiradical and antimicrobial properties of coldpressed black cumin and cumin oils. Europen Food Research Technology 234:833-844

Rebey I B, Jabri-Karoui I, Hamrouni-Sellami I, Bourgou S, Limam F \& Marzouk B (2012). Effect of drought on the biochemical composition and antioxidant activities of cumin (Cuminum cyminum L.) seeds. Industrial Crops and Products 36:238-245

Ruberto G \& Baratta M T (2000). Antioxidant activity of selected essential oil components in two lipid model systems. Food Chemistry, 69(2): 167-174

Skalicka-Woz'niak K, Walasek M, Ludwiczuk A \& Głowniak K (2013). Isolation of terpenoids from Pimpinella anisum essential oil by high-performance counter-current chromatography. journal of Seperation Science 36(16), 2611-2614

Sultana S, Ripa F A \& Hamid K (2010). Comparative antioksidant activity study of some comonly used spices in Bangladesh. Pakistan Journal of Biological Science 13(7):340-343

Tepe B, Akpulat A H, Sokmen M, Daferera D, Yumrutas O, Aydin E, Polissiou M \& Sokmen A (2006). Screening of the antioxidative and antimicrobial properties of the essential oil of Pimpinella anisetum and Pimpinella flabellifolia from Turkey. Food Chemistry. 97(4): 719-724

Thippeswamy, N B \& Naidu K A (2005). Antioxidant potency of cumin varieties cumin, black cumin and bitter cumin-on antioxidant systems. European Food Research and Technology 220(5-6): 472-476

Tirapelli C R, Andrade C R., Cassano A O, De Souza F A, Ambrosio S R, Costa F B \& Oliveria A M (2007). Antispasmodic and relaxant effects of the hydroalcoholic extract of Pimpinella anisum (Apiaceae) on rat anococcygeous smooth muscle. Journal of Ethnopharmacology 110(1): 23-29

Tunc I \& Sahinkaya S (1998). Sensitivity of two greenhouse pests to vapours of essential oils. Entomologia Experimentalis et Applicata 86(2): 183187

Vardar-Ünlü G, Candan F, Sokmen A, Daferera D, Polissiou M, Sokmen M, Donmez E \& Tepe B (2003). Antimicrobial and antioxidant activity of the essential oil and methanol extracts of Thymus pectinatus fisch. et mey. var. pectinatus (Lamiaceae) Journal of Agricultural and Food Chemistry 51(1): 63-67

Yan F, Beyer E M, Azizi A \& Honermeier B (2011). Effects of sowing time and sowing density on fruit yield, essential oil concentration and composition of anise (Pimpinella anisum L.) under field conditions in Germany. Journal of Medicinal Spice Plants 16: 26-33 